\title{
GALANTAMINE ANTIACETYLCHOLINESTERASE ACTIVITY IN RAT BRAIN INFLUENCED BY L-CARNITINE
}

\author{
Zbyněk Svoboda ${ }^{a}$, Jaroslav Květina ${ }^{\mathrm{a}}$, Josef Herink ${ }^{\mathrm{a}}$, Jiří Bajgar ${ }^{\mathrm{b}}$, Lucie Bartošováb, \\ Vladimír Palička ${ }^{c}$, Pavel Živnýc
}

\author{
a Institute of Experimental Biopharmaceutics, Joint Research Centre of the Czech Academy of Sciences and PRO.MED.CS \\ Praha a.s., Hradec Králové, Czech Republic \\ ${ }^{b}$ Faculty of Military Health Sciences, University of Defence, Hradec Králové, Czech Republic \\ c Faculty of Medicine, Charles University, Hradec Králové, Czech Republic \\ e-mail: svoboda@uebf.cas.cz
}

Received: June 10, 2005; Accepted: September 25, 2005

Key words: Galantamine/Acetylcholinesterase/L-Carnitine/Brain/Rat/Alzheimer's disease

\begin{abstract}
Galantamine (GAL) is a selective, competitive and reversible acetylcholinesterase (AChE) inhibitor, which increases the activity of the cholinergic system and hence gives rise to an improvement of cognitive functions in patients suffering from dementia of Alzheimer type. L-Carnitine (CAR) is a natural component of the mammalian tissue and is known to increase penetration of some chemical compounds/groups across biological membranes. The aim of this study was to evaluate the influence of pretreatment with CAR on AChE inhibition caused by GAL in selected brain parts in rat (basal ganglia, septum, frontal cortex, hippocampus) and in hypophysis, which does not lay beyond the blood-brainbarrier. During the first stage of the study, GAL was administered i.m. in different doses ranging from 2.5 to $10 \mathrm{mg} / \mathrm{kg}$. The highest degree of AChE dose dependent inhibition was observed in hypophysis, while that in CNS was lower and became apparent in frontal cortex and hippocampus only after the administration of the dose of $10 \mathrm{mg} / \mathrm{kg}$ i.m. In the second stage, CAR was administered daily during 3 consecutive days at a dose of $250 \mathrm{mg} / \mathrm{kg}$ p.o. prior to the administration of GAL ( $10 \mathrm{mg} / \mathrm{kg}$ i.m.). Pretreatment with CAR enhanced trend of AChE inhibition in all selected brain parts comparing with single GAL administration, however, significant difference was not observed. Comparing these results with control group, statistical significance was found in frontal cortex, hippocampus and hypophysis.
\end{abstract}

\section{INTRODUCTION}

Galantamine (GAL) is a selective, competitive and reversible acetylcholinesterase (AChE, EC 3.1.1.7) inhibitor. It works by inhibiting AChE and by allosterically modulating nicotinic receptors. Although galantamine was first used as a reverser of neuromuscular blockade, it has recently been studied and shown to be effective for use in the treatment of Alzheimer's disease, vascular dementia and Alzheimer's disease with cerebrovascular disease. Patients receiving galantamine showed significant improvement in the areas of cognition global function, activities of daily living and behaviour ${ }^{1}$.

L-Carnitine (CAR) is a natural component of mammalian tissue and plays an important physiological role, in particular, in $\beta$-oxidation because it facilitates long-chain fatty acid transport across the inner mitochondrial membrane. Moreover, CAR is known to increase penetration of some drugs or chemical groups through biological barriers ${ }^{2}$.

The main goal of this work was to investigate a possible modulation of galantamine targeting towards central nervous system (CNS) by L-carnitine pretreatment, and hence, enhance galantamine antiacetylcholinesterase activity in the rat brain, as it was previously reported by our laboratory with another AChE inhibitor 7-methoxytacrine ${ }^{3}$.

\section{MATERIAL AND METHODS}

Animals

Male Wistar Han II rats (BioTest Ltd., Konárovice, Czech Republic), weighing $270 \pm 23 \mathrm{~g}$, were used in the study. Animals were fasted with water ad libitum for 12 hours prior to administration of GAL. The study was approved by the Ethical Committee of the Czech Academy of Sciences.

\section{Chemicals}

Galantamine hydrobromide (purity > $99 \%$ ) was purchased from ICN Biomedicals, Inc. (USA), L-carnitine hydrochloride (purity > $99 \%$ ) was purchased from SigmaAldrich (USA).

\section{Assessing the effective dose of GAL}

In order to select a suitable dose of GAL for subsequent experiments, GAL was applied intramuscularly to three groups $(n=7)$ of experimental animals in single 

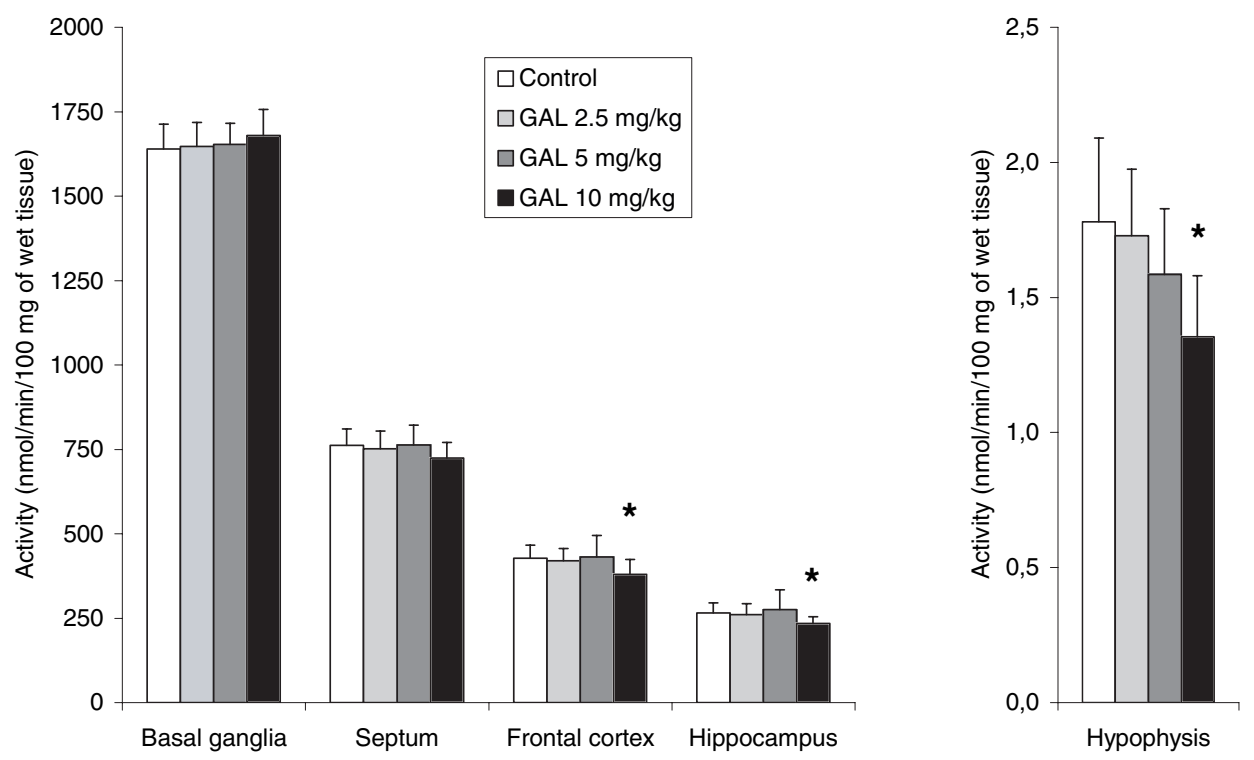

Fig. 1. Activity of $\mathrm{AChE}$ in selected brain parts 30 minutes after i.m. administration of different doses of GAL in rats. Statistical significance is calculated against control group $(*=\mathrm{P}<0.05)$.
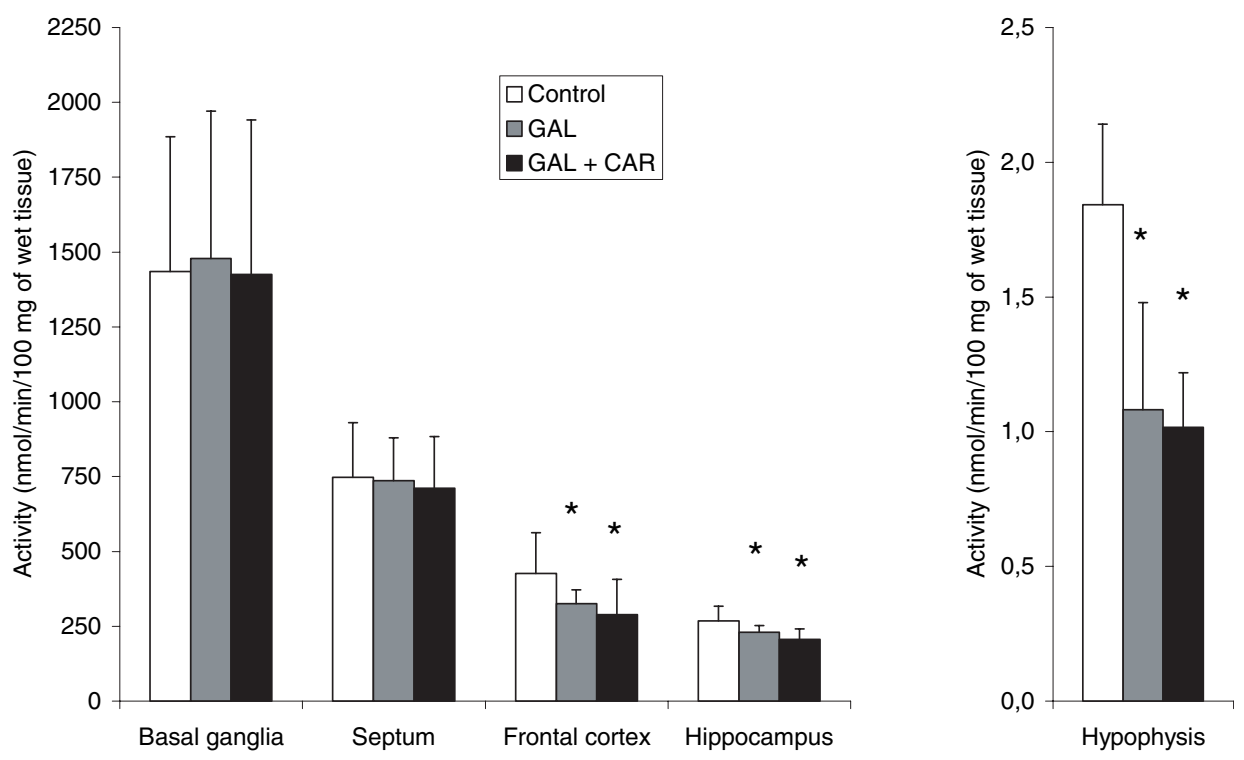

Fig. 2. Activity of $\mathrm{AChE}$ in selected brain parts 30 minutes after intramuscular administration of GAL ( $10 \mathrm{mg} / \mathrm{kg}) \mathrm{in} \mathrm{rats}$ not pretreated or pretreated with CAR. Statistical significance is calculated against control group $(*=\mathrm{P}<0.05)$.

doses of $2.5 \mathrm{mg} / \mathrm{kg}$ (twice the highest therapeutic dose for humans), 5 and $10 \mathrm{mg} / \mathrm{kg}$. Cholinesterase activity was measured after 30 minutes following GAL administration in those parts of the brain, which possess a different activity of the cholinergic system ${ }^{4}$ (in basal ganglia, septum, frontal cortex and hippocampus) and also in hypophysis which does not lie beyond the blood brain barrier (BBB).
Ifluence of pretreatment with CAR on AChE inhibition caused by GAL

The animals were divided into three groups with seven in each. The control group of animals was administered daily with water by gavage during three consecutive days. 30 min after the last dose of water, saline was administered intramusculary (i.m.). 30 min later, the animals were killed and exsanguinated. Brain parts (basal ganglia, septum, frontal cortex and hippocampus) and hypophysis were collected for further determination of AChE activity. The first experimental group was administered i.m. with 
GAL in the form of saline solution at a dose of $10 \mathrm{mg} / \mathrm{kg}$. After $30 \mathrm{~min}$ the tissue samples were collected. The second experimental group was administered with CAR at a daily dose of $250 \mathrm{mg} / \mathrm{kg}$ by gavage during three consecutive days and $30 \mathrm{~min}$ after the last dose of CAR, GAL was injected i.m. (10 mg/kg).

\section{Determination of AChE activity}

The all tissue samples were homogenized in distilled water. The determination of AChE activity was done using the method of Ellman et al. ${ }^{4}$ and was expressed as $\mathrm{nmol} / \mathrm{min} / 100 \mathrm{mg}$ of wet tissue.

\section{Statistical analysis}

All the data are reported as mean \pm SD. Statistical comparison of the data was done by Student's $t$-test at a significance level of $\mathrm{P}<0.05$.

\section{RESULTS AND DISCUSSION}

The highest degree of $\mathrm{AChE}$ dose-dependent inhibition after the administration of different GAL doses was observed in the hypophysis, while that in the CNS was lower. It can be explain by the fact that hypophysis does not lie beyond the BBB. Statistical significant inhibition became apparent in the frontal cortex and hippocampus only after the administration of the dose of $10 \mathrm{mg} / \mathrm{kg}$ (Fig. 1), thus, the effective GAL dose was determined to be $10 \mathrm{mg} / \mathrm{kg}$ i.m.

Following administration of lower doses, any statistical significance was not found (in vitro), nevertheless, many of clinical signs of AChE inhibition were observed (eg. tremor, convulsions, salivation) even after the administration of the dose of $2.5 \mathrm{mg} / \mathrm{kg}$. According to these observations a behavioral test was performed in rats with the aim to evaluate a peripheral and central activity of cholinergic system. It was found that the clinical signs of AChE inhibition have their origin mainly in the peripheral inhibition of AChE (results are not published here).
The highest degree of AChE activity was found in basal ganglia. GAL did not cause any inhibition of AChE activity in this brain part.

Pretreatment with CAR led to a higher inhibition of AChE in all selected brain parts comparing with single GAL administration (Fig. 2). However, significant difference was not observed. Only in hippocampus, a statitistical significance was nearly reached. Comparing with control group, a statistical significance was found in frontal cortex, hippocampus and hypophysis.

Regardless of relatively high interindividual differences of AChE activity, it seems that the most sensitive brain area is frontal cortex and hippocampus. A relative sensitivity of the frontal cortex was observed also in case of other substances, eg. 7-methoxytacrine ${ }^{3}$ and various organophosphates ${ }^{6}$, as well.

\section{ACKNOWLEDGEMENT}

Financial support by the grant No. NR7935-3/2004 of the IGA MZ ČR is gratefully acknowledged.

\section{REFERENCES}

1. Farlow MR. (2003) Clinical pharmacokinetics of galantamine. Clin Pharmacokinet 42, 1383-92.

2. Evans AM, Fornasini G. (2003) Pharmacokinetics of L-carnitine. Clin Pharmacokinet 42, 941-67.

3. Svoboda Z, Herink J, Bajgar J, Květina J. (2001) The influence of L-carnitine on biodistribution and effect of 7-methoxytacrine in rat. Homeostasis 41, 49-51.

4. König JFR, Klippel RA. The rat brain. Baltimore: Williams and Wilkins Co., 1963.

5. Ellman GL, Courtney DK, Andres V, Featherstone RM. (1961) A new and rapid colorimetric determination of acetylcholinesterase activity. Biochem Pharmacol 7, 88-95.

6. Bajgar J, Herink J, Fusek J. (2001) Changes of individual molecular forms of the rat brain acetylcholinesterase following administration of nerve agents. Homeostasis 41, 233-6. 